\title{
The Immediate Effects of Pulse Steroid versus Common Steroid therapy in Patients with SSNHL
}

\author{
Mohammadhossein Baradaranfar ${ }^{1}$, Amrollah Dehghani ${ }^{1}$, Vahid Zand ${ }^{1 *}$, Sedighe Vaziribozorg ${ }^{1}$
}

1 Department of Otolaryngology- Head and Neck Surgery, Otorhinolaryngology Research Center, Shahid Sadoughi University of Medical Sciences, Yazd, Iran

*Corresponding Author: Vahid Zand, MD, Department of Otolaryngology Head and neck surgery, Otorhinolaryngology Research Center, Shahid Sadoughi Hospital, Avicenna Blvd, Safaiyeh, Yazd, Iran.

Email: drvzand@gmail.com, Tel: +9835 3183368, Fax: +9835 38224100

\begin{abstract}
Introduction: In this study we aimed to review immediate effects of pulse steroid therapy versus common steroid therapy in patients with idiopathic Sudden Sensory- Neural Hearing Loss. Materials and Methods: In this clinical trial study 50 patients with SSNHL in less than 24 hours before referral were involved. The causes of hearing loss should be rejected and if the cause was identified, the patient would be excluded. Pulse therapy group received Methyl Prednisolone $10 \mathrm{mg} / \mathrm{kg}$ for three days and then continued by prednisolone $1 \mathrm{mg} / \mathrm{kg}$ for ten days and common therapy group received prednisolone $1 \mathrm{mg} / \mathrm{kg}$ for ten days. Average hearing threshold of the patients in frequencies of 500, 1000, and 2000 Htz, average SDS of patients and patient recovery was compared between two groups based on hearing tests and guidelines. Results: Fifty patients with average of $46 \pm 15.69$ years were studied. There was no significant difference in average of hearing threshold in different frequencies and SDS between two groups. Mean hearing recovery was $10.69 \mathrm{db}$ in common steroid group and it was $13.51 \mathrm{db}$ in pulse steroid group. Although the mean of hearing recovery was higher in the pulse steroid group compare the common steroid group, there was no significant difference in hearing recovery after the treatment between two groups. Conclusion: According to the results pulse steroid is not preferable rather than common steroid therapy in terms of immediate therapeutic effects on SSNHL.
\end{abstract}

Keywords: Pulse Steroid Therapy, Common Steroid Therapy, SSNHL.

\section{INTRODUCTION}

Sudden sensory- neural hearing loss is one of the emergencies and the most controversy audiology diseases [1]. Its symptoms can include unilateral or bilateral hearing loss, sense of fullness of ears, tinnitus, dizziness, and imbalance ${ }^{[1-3]}$. Since the disease is sudden, it results in high stress in the patients causing complications such as permanent hearing loss and tinnitus [4] which can effect on quality of patient's life. Prevalence of this disease has increased to 4000 new case annually with frequency of 5-20 people in each 100000 people of the population ${ }^{[5-8]}$. In spite of the numerous researches on the causes of the disease, the risk factors has not been identified completely $[9,10]$ and no certain treatment for it has been introduced yet. On the other hand, due to the large number of its etiologies, no treatment has been satisfactory [11]. Moreover, due to broad pathology of the disease, presence of patients who improve spontaneously, and delay in referral to specialists, there is a low number of controlled studies on different aspects of this disease ${ }^{[12,13]}$; therefore, there are various treatments which are broadly empirical ${ }^{[14]}$. One of the most important etiologic factors of sudden sensory- neuropathy hearing loss is autoimmune factor $[15,16]$. Thus, this study aimed to review the immediate therapeutic results of pulse therapy comparing common steroid therapy in patients with SSNHL.

\section{METHODOLOGY}

After approval by ethics committee and obtaining written informed consent, in this clinical trial study 50 patients with SSNHL (hearing loss above $30 \mathrm{~dB}$ in at least three consecutive frequencies) in less than 24 hours before referral without any previous history of ear diseases were involved. Patients who had hearing loss occurring more than 2 days before evaluation and had contraindication to the use of high-dose steroids were excluded. The causes of hearing loss should be rejected regarding the description, physical examination, performing laboratory tests and MRI of $\mathrm{CP}$ angle and temporal bone (if hearing loss was unilateral) and if the cause was identified, the patient would be excluded too. The patients were divided into two groups using random numbers table. The first group (pulse 
therapy) received Methyl Prednisolone $10 \mathrm{mg} / \mathrm{kg}$ for three days and then continued by prednisolone $1 \mathrm{mg} / \mathrm{kg}$ for ten days. The second group (common therapy) received prednisolone $1 \mathrm{mg} / \mathrm{kg}$ for ten days. Average hearing threshold of the patients in both groups in frequencies of 500,1000, and $2000 \mathrm{Htz}$ before and after the treatment was compared. Average SDS of Patients in both groups was also compared before and after the treatment. In addition, patient recovery (complete, relative, and no recovery) was evaluated based on the AAO-HNSF (American Academy of Otolaryngology - Head and Neck Surgery Foundation) guideline (Table.1). All data analyzed by SPSS Software version 22. P-value $\leq 0.05$ considered significant.

Table 1: Hearing Recovery Classification based on the AAO-HNSF guideline

1. Full recovery: Return to $10 \mathrm{~dB}$ difference in hearing compared to non-involved ear

2. Relative recovery: Based on whether the degree of hearing loss is * serviceable or non-serviceable after SSNHL:

A. For the cases that reach non serviceable level after SSNHL, hearing improvement from non-serviceable to serviceable hearing is considered as a relative recovery and recovery less than a serviceable level is considered without recovery.

B. In cases which are still at the serviceable level after SSNHL, $10 \mathrm{~dB}$ hearing improvement in PTA is considered as a relative recovery.

3. No recovery: Hearing improvement less than $10 \mathrm{~dB}$ is considered as no-recovery.

*(Non serviceable hearing: $\leq 50 \%$ SDS and $\geq 50 \mathrm{~dB}$ on PTA)

\section{RESULTS}

In this clinical trial study 50 patients with the average age of 46 \pm 15.69 years were studied. Twenty patients were females (40\%) and 30 were males (60\%). According to the results, in the group receiving common therapy, average of hearing threshold in frequencies of 500, 1000, and $2000 \mathrm{Htz}$ was significantly lower after the treatment. Also SDS average was significantly lower after the treatment in this group ( $p$-value $=0.00)($ Table.2). In the group receiving pulse therapy, average of hearing threshold in frequencies of 500, 1000, and 2000 was significantly lower after the treatment and SDS average was significantly lower after the treatment too ( $p$-value $=0.00)$ ( Table.3). Comparing two groups, there was no significant difference in immediate therapeutic effects of pulse steroid therapy versus common steroid therapy (including average of hearing threshold in different frequencies and SDS) on SSNHL (Table.4). Finally, according to the results, mean hearing recovery was $10.69 \mathrm{db}$ in common steroid therapy group and it was $13.51 \mathrm{db}$ in pulse steroid group. Although the mean of hearing recovery was higher in pulse steroid group compare with common steroid group, there was no significant difference in hearing recovery after the treatment between two groups (Table. 5).

Table 2: Average of hearing threshold before and after the treatment with common steroid therapy.

\begin{tabular}{|l|l|l|l|}
\hline Frequencies & Before treatment & After treatment & P-value \\
\hline $500 \mathrm{Htz}$ & $60.5 \pm 23.4$ & $46.82 \pm 28.64$ & 0.000 \\
\hline $1000 \mathrm{Htz}$ & $57.5 \pm 26.67$ & $46.36 \pm 30.55$ & 0.000 \\
\hline $2000 \mathrm{Htz}$ & $54.32 \pm 30.01$ & $47.05 \pm 32.24$ & 0.020 \\
\hline PTA & $57.44 \pm 26.69$ & $46.74 \pm 30.48$ & 0.000 \\
\hline SDS & $50.59 \pm 35.83$ & $74.14 \pm 29.95$ & 0.000 \\
\hline
\end{tabular}

Table 3: Average of hearing threshold before and after treatment with pulse steroid

\begin{tabular}{|l|l|l|l|}
\hline Frequencies & Before treatment & After treatment & P-value \\
\hline $500 \mathrm{Htz}$ & $60.71 \pm 27.57$ & $45.54 \pm 24.58$ & 0.020 \\
\hline $1000 \mathrm{Htz}$ & $61.43 \pm 28.57$ & $48.21 \pm 24.69$ & 0.020 \\
\hline $2000 \mathrm{Htz}$ & $64.46 \pm 32.18$ & $52.32 \pm 27.26$ & 0.010 \\
\hline PTA & $62.2 \pm 29.44$ & $48.69 \pm 25.51$ & 0.010 \\
\hline SDS & $55.64 \pm 29.51$ & $76.25 \pm 28.91$ & 0.010 \\
\hline
\end{tabular}

Table 4: Therapeutic effects of Pulse steroid therapy and common steroid therapy

\begin{tabular}{|l|l|l|l|}
\hline Frequencies & $\begin{array}{l}\text { Treatment } \\
\text { with pulse } \\
\mathrm{N}=28\end{array}$ & $\begin{array}{l}\text { Common steroid } \\
\text { therapy } \\
\mathrm{N}=\mathbf{2 2}\end{array}$ & P-value \\
\hline $500 \mathrm{Htz}$ & $45.54 \pm 24.58$ & $46.82 \pm 28.64$ & 0.343 \\
\hline $1000 \mathrm{Htz}$ & $48.21 \pm 24.69$ & $46.36 \pm 30.55$ & 0.252 \\
\hline $2000 \mathrm{Htz}$ & $52.32 \pm 27.26$ & $47.05 \pm 32.24$ & 0.306 \\
\hline SDS & $76.25 \pm 28.91$ & $74.14 \pm 29.95$ & 0.626 \\
\hline
\end{tabular}

Table 5: Hearing recovery after treatment between the two groups

\begin{tabular}{|l|l|l|l|l|}
\hline Variable & \multicolumn{2}{|l|}{ Groups } & P-value \\
\cline { 2 - 5 } \multicolumn{2}{|l|}{$\begin{array}{l}\text { Pulse steroid } \\
\text { therapy } \\
\mathbf{N}=\mathbf{2 8}\end{array}$} & $\begin{array}{l}\text { Common steroid } \\
\text { therapy } \\
\mathbf{N = 2 2}\end{array}$ & \\
\hline Recovery & complete & 5 & 4 & 0.48 \\
\cline { 2 - 5 } & Relative & 16 & 13 & 0.48 \\
\cline { 2 - 5 } & No recovery & 7 & 5 & 0.53 \\
\hline Mean hearing recovery & $13.51 \mathrm{db}$ & $10.69 \mathrm{db}$ & $>0.05$ \\
\hline
\end{tabular}


Sudden sensory- neural hearing loss is one the most complex diseases in otorhinolaryngology about which there are various controversies believe ${ }^{[6]}$. There are even differences in defining this disease, but the most consensus definition is that hearing loss above $30 \mathrm{~dB}$ in at least three consecutive frequencies which is developed in less than three hours is called sudden sensoryneural hearing loss $[6,17,18]$. More than 100 causes can be involved for it. Although most of cases of the disease have remained idiopathic, various pathologic factors such as viral infections, autoimmune mechanisms, vascular disorders and ischemic events have been reported for sudden sensory- neural hearing loss $[6,17]$. Different treatments for improving idiopathic sudden sensory- neural hearing loss have been suggested in different studies. In this study we aimed to review immediate effects of pulse steroid therapy versus common steroid therapy in patients with idiopathic Sudden Sensory- Neural Hearing Loss. The results of the present study showed that both therapeutic treatments were individually effective; however, the treatment with pulse steroid was not significantly different from the common steroid therapy in terms of immediate therapeutic effect on sensory- neural hearing loss. Also although the mean of hearing recovery was higher in the pulse steroid group compare with common steroid group, there was no significant difference in mean hearing recovery after the treatment between two groups. In the study by Eftekharian et al. 34 patients were treated with intravenous methylprednisolone with the dose of $500 \mathrm{mg}$ for three days, and then they received oral prednisolone $1 \mathrm{mg} / \mathrm{kg}$ for 11 days. Hearing change was evaluated by comparing initial hearing tests and the thirdmonth hearing tests. The results of their study showed that there was no significant difference between the treatment with pulse steroid and the common steroid therapy and produced similar results in improving idiopathic sudden sensory- neural hearing loss [19]. This finding is compatible with the findings of the present study. Wester laken et al. conducted a retrospective doubleblind study on 81 patients with idiopathic SSNHL. They treated patients with $300 \mathrm{mg}$ of Dexamethasone for three days and then placebo for four days. The patients in control group were treated with $70 \mathrm{mg}$ of prednisolone per day for seven days; in a way that the amount of prednisolone tapered from $70 \mathrm{mg}$ to $0 \mathrm{mg}$. In line with our study, they founded that there was no significant difference between two groups in overall improvement of puretone thresholds and speech discrimination scores after 12 months ${ }^{[20]}$. In contrast with our findings, the results of a study by Aoki et al. on 112 patients with SSNHL indicated that treatment with initial dose of $1200 \mathrm{mg}$ of Hydrocortisone was more effective than the treatment with initial dose of $600 \mathrm{mg}$ of Hydrocortisone and the patients treated with initial dose of 1200 mg of Hydrocortisone exhibited significantly superior complete recovery rate and improvement rate ${ }^{[21]}$. Also the results of a study by Siow et al. on three patients with idiopathic sudden sensory- neural hearing loss showed that patients with severe idiopathic sudden SSNHL could achieve better results with high doses of steroid for three days; in addition, the patients' audiogram significantly improved 2, 4 and six weeks after the treatment ${ }^{[22]}$. Various results from different studies can be due to different doses of steroids, different treatment periods and different sample sizes ${ }^{[22-25]}$

\section{CONCLUSION}

The results of this study indicated that despite the effectiveness of common steroid therapy and pulse steroid therapy on SSNHL, there was no significant difference in mean hearing recovery after treatment between two groups and pulse steroid was not preferable rather than common steroid therapy in terms of immediate therapeutic effects on SSNHL.
- $\quad$ Authors have no conflicts of interest.

- Study protocol was in accordance with the latest Declaration of Helsinki for medical research involving human subjects and was approved by local ethics committee.

- This article does not contain any studies with animals performed by any of the authors.

- Informed consent was obtained from all participants of the study.

\section{REFERENCES}

1. Yimtae K, Srirompotong S, Kraitrakul S. Idiopathic sudden sensorineural hearing loss. Journal of the Medical Association of Thailand= Chotmaihet thangphaet. 2001; 84(1):113-9.

2. Zhong L-P, Wang L-Z, Ji T, Yang W-J, Zhang C-P. Management of facial nerve schwannoma in the accessory parotid region. Journal of Oral and Maxillofacial Surgery. 2011; 69(5):1390-7.

3. Stachler RJ, Chandrasekhar SS, Archer SM, Rosenfeld RM, Schwartz SR, Barrs DM, et al. Clinical practice guideline: sudden hearing loss. Otolaryngology-Head and Neck Surgery. 2012; 146(3 suppl):S1-S35.

4. Cho $\bar{S}$, Chen H, Kim IS, Yokose C, Kang J, Cho D, et al. Association of the $4 \mathrm{~g} / 5 \mathrm{~g}$ polymorphism of plasminogen activator inhibitor-1 gene with sudden sensorineural hearing loss. A case control study. BMC Ear, Nose and Throat Disorders. 2012; 12(1):5.

5. Chung SY, Kim DI, Lee BH, Yoon PH, Jeon P, Chung TS. Facial nerve schwannomas: CT and MR findings. Yonsei Med J. 1998; 39(2):148-53.

6. Schweinfurth JM, Cacace AT, Parnes SM. Clinical applications of otoacoustic emissions in sudden hearing loss. The Laryngoscope. 1997; 107(11):1457-63.

7. Mehta RP, Deschler DG. Intraoperative diagnosis of facial nerve schwannoma at parotidectomy. American journal of otolaryngology. 2008; 29(2):126-9.

8. Fyrmpas G, Konstantinidis I, Hatzibougias D, Vital V, Constantinidis J. Intraparotid facial nerve schwannoma: management options. European Archives of Oto-RhinoLaryngology. 2008; 265(6):699-703.

9. Shimizu K, Iwai H, Ikeda K, Sakaida N, Sawada S. Intraparotid facial nerve schwannoma: a report of five cases and an analysis of MR imaging results. American journal of neuroradiology. 2005; 26(6):1328-30.

10. Chiang C-W, Chang Y-L, Lou P-J. Multicentricity of intraparotid facial nerve schwannomas. Annals of Otology, Rhinology \& Laryngology. 2001; 110(9):871-4.

11. Sibbald B. Patient self care in acute asthma. Thorax. 1989; 44(2):97-101.

12. Subbarao P, Mandhane PJ, Sears MR. Asthma: epidemiology, etiology and risk factors. Canadian Medical Association Journal. 2009; 181(9):E181-E90.

13. Organization WH. Asthma Fact sheet No 307. 2013. 2016.

14. Kronenberg J, Almagor M, Bendet E, Kushnir D. Vasoactive therapy versus placebo in the treatment of sudden hearing loss: A double-blind clinical study. The Laryngoscope. 1992; 102(1):65-8.

15. Nakashima T, Tanabe T, Yanagita N, Wakai K, Ohno Y. Risk factors for sudden deafness: a case-control study. Auris Nasus Larynx. 1997; 24(3):265-70.

16. Zadeh MH, Storper IS, Spitzer JB. Diagnosis and treatment of sudden-onset sensorineural hearing loss: a study of 51 patients. Otolaryngology — Head and Neck Surgery. 2003; 128(1):92-8.

17. Arts HA. Sensorineural hearing loss: evaluation and management in adults. Cummings CW, Flint PW, Harker LA, Haughey BH, Richardson MA, Robbins KT, et al. Cummings Otolaryngology Head and Neck Surgery 4th ed Philadelphia: Elsevier Mosby. 2005:3550-5.

18. Tlumak Al, Kileny PR. Parameters that affect the measurement of otoacoustic emissions. Current Opinion in Otolaryngology \& Head and Neck Surgery. 2001; 9(5):279-83. 
19. Eftekharian A, Amizadeh M. Pulse steroid therapy in idiopathic sudden sensorineural hearing loss: A randomized controlled clinical trial. The Laryngoscope. 2016; 126(1):150-5.

20. Westerlaken BO, de Kleine E, van der Laan B, Albers F. The Treatment of Idiopathic Sudden Sensorineural Hearing Loss Using Pulse Therapy: A Prospective, Randomized, Double-Blind Clinical Trial. The Laryngoscope. 2007; 117(4):684-90.

21. Aoki D, Takegoshi H, Kikuchi S. Evaluation of super-high-dose steroid therapy for sudden sensorineural hearing loss. Otolaryngology-Head and Neck Surgery. 2006; 134(5):783-7.

22. Siow SF, Parratt J, Satyan H, Cremer P. High dose intravenous steroids as first line treatment for severe idiopathic sudden sensorineural hearing loss (P5. 199). Neurology. 2017; 88(16 Supplement):P5. 199.

23. Battaglia A, Burchette $R$, Cueva $R$. Combination therapy (intratympanic dexamethasone+ high-dose prednisone taper) for the treatment of idiopathic sudden sensorineural hearing loss. Otology \& Neurotology. 2008; 29(4):453-60.

24. Hultcrantz E, Nosrati-Zarenoe R. Corticosteroid treatment of idiopathic sudden sensorineural hearing loss: analysis of an RCT and material drawn from the Swedish national database. European Archives of Oto-Rhino-Laryngology. 2015; 272(11):3169-75.

25. Kang H-S, Park JJ, Ahn S-K, Hur DG, Kim H-Y. Effect of high dose intravenous vitamin $\mathrm{C}$ on idiopathic sudden sensorineural hearing loss: a prospective single-blind randomized controlled trial. European Archives of Oto-Rhino-Laryngology. 2013; 270(10):2631-6. 